\title{
FORMAÇÃO DOCENTE NA EDUCAÇÃO DE JOVENS E ADULTOS: ESPECIFICIDADES, IDENTIDADES E POLÍTICAS PÚBLICAS
}

\author{
Márcio Fernando Silva ${ }^{1}$, Santuza Amorim Silva ${ }^{2}$ \\ ${ }^{1}$ Mestre em Educação pela Universidade do Estado de Minas Gerais - UEMG, Analista Educacional pela Secretaria de \\ Estado de Educação de Minas Gerais - SEE/MG. E-mail: mfsneo@gmail.com \\ ${ }^{2}$ Doutora em Educação pela Universidade Federal de Minas Gerais - UFMG, doutorado sanduíche pelo INRP (Institut \\ Nacional de Recherche Pédagogigue). Docente do Curso de Pedagogia e do Mestrado em Educação da Universidade \\ do Estado de Minas Gerais - UEMG.
}

\section{RESUMO}

Este trabalho apresenta uma reflexão analítica do campo da formação docente na Educação de Jovens e Adultos. Objetivou-se, por meio da análise e da contextualização de produções bibliográficas do campo em questão, delinear as especificidades, as identidades e as políticas públicas da formação docente na Educação de Jovens e Adultos, de acordo com as necessidades históricas e específicas da formação de professores/as na EJA. Nesse contexto, observou-se a necessidade de refletir criticamente sobre o processo de formação docente na EJA e de (re) avaliar as possibilidades e/ou as intencionalidades desse processo. Entende-se, por meio dos resultados obtidos, que as experiências formativas têm que estimular o desenvolvimento e a reflexão acerca das teorias e das metodologias docentes previamente adquiridas nos cursos de formação, demonstrando que a continuidade do aprendizado docente é algo inerente à prática da atividade educacional. Dessa forma, é preciso reforçar os debates em torno da emergência de resoluções que ampliem a potencialidade docente na Educação de Jovens e Adultos, incentivando o aperfeiçoamento dos processos formativos na EJA, mediante políticas públicas efetivas de formação profissional docente nessa modalidade de educação.

Palavras-chave: Formação Docente. Educação de Jovens e Adultos. Educadores de Jovens e Adultos.

\section{TEACHER TRAINING IN ADULT EDUCATION: SPECIFICITIES, IDENTITIES AND PUBLIC POLICIES}

\section{ABSTRACT}

This paper presents an analytical reflection on teacher education in Adult Education. The objective of this study was to analyze and to contextualize the bibliographical productions about this teacher training, delineating the specificities, identities and public policies of teacher training in Adult Education, according to the historical and specific needs of teacher education in the Adult Education. In this context, it was observed that it is necessary to reflect critically on the process of teacher training in the Adult Education and to re-evaluate the possibilities and the intentionalities of this process. It is understood that the formative experiences have to stimulate the development and the reflection about the theories and the teaching methodologies previously acquired in the training courses, establishing, that the continuity of the teaching learning is something inherent to the practice of the educational activity. It is necessary to reinforce the debates around the emergence of resolutions that increase the teaching potential in the Education Adults, encouraging the improvement of the training processes in the Adult Education, through effective public policies of professional teacher training in this type of teaching.

Keywords: Teacher Training. Adult Education. Youth Educators.

\section{INTRODUÇÃO}

Em um momento como o atual, repleto de incertezas acerca das deliberações para com as políticas educacionais futuras, tornam-se significativos os debates sobre as dimensões das propostas de formação profissional docente e a relação dessas propostas com a diversidade social e cultural. Os processos de formação docente 
passam por um momento complexo e cheio de incertezas, o que leva à necessidade de reflexões acerca da construção de uma prática docente contextualizada com o presente (NÓVOA, 2007).

Os cursos de licenciaturas não têm capacitado inteiramente seus estudantes para lidar com as realidades encontradas nas salas de aulas, quando em prática de ofício. Nesse sentido, Nóvoa (2009) pondera que as discussões a respeito da formação docente devem ocupar um lugar central nos debates sobre uma educação autônoma e situada na conjuntura hodierna. Seguindo essa linha de pensamento, é preciso reconhecer as deficiências conceituais dos programas de formação docente na atualidade e desenvolver propostas que incorporem dimensões formativas de diversidade intelectual e cultural, para que possamos superar processos formativos defasados e inconsistentes com as demandas da contemporaneidade. Tratase, nesse contexto, de situar a formação docente a partir de bases mais coerentes com as demandas da sociedade atual, rompendo, assim, com paradigmas conservadores, que não estejam em equilíbrio com as realidades e as vivências do campo profissional.

Arroyo (2015) avalia que as diretrizes de formação de educadores possuem uma história tensa nas políticas públicas pela igualdade do direito à educação. $O$ profissional docente também se configura como um sujeito de direitos e a formação profissional deste necessita de reflexões a respeito das políticas relacionadas às diretrizes nacionais de formação. As configurações sobre o perfil de profissional docente almejado devem ser claras e objetivas, não se permitindo a prevalência de concepções formativas baseadas somente em conteúdos teóricos, sem a necessária reflexão da prática e ausente de interdisciplinaridade. Nesse sentido, Arroyo (2015) ainda esclarece que a educação se faz por meio de relações sociais, políticas e econômicas e que a igualdade escolar, no sentido de equidade de oportunidades, somente é alcançada por meio da igualdade social. Entendese que os profissionais em educação necessitam de uma formação que aborde concepções voltadas para a diversidade e a igualdade social, no intuito de ampliar paradigmas e equacionar disparidades.

Nesse contexto, A Educação de Jovens e Adultos (EJA), como modalidade de educação, carece de propostas formativas que definam e orientem uma formação específica de professores para atuação nesse segmento educacional. Faz-se necessária, então, uma argumentação em favor de uma política de formação de educadores que considere os contextos históricos dos estudantes jovens e adultos, perfazendo os contornos formativos que a Educação de Jovens e Adultos tanto reivindica (BORGHI, 2007). Nessa perspectiva, Soares (2008) expõe que a formação docente do educador de jovens e adultos não é um tema necessariamente novo, mas, somente nas últimas décadas, ganhou dimensão mais ampla. Os avanços constitucionais recentes e a contínua luta dos movimentos sociais certamente favoreceram a oferta de ensino para o público jovem e adultos. No entanto, a relevância destinada à EJA e, consequentemente, a formação docente dessa modalidade, no cenário educacional, ainda permanecem aquém da real necessidade.

Seguindo essa linha argumentativa, Ribas e Soares (2012) consideram primordial a busca por uma formação docente inovadora para com o educador de jovens e adultos. Almeja-se, nesse sentido, um percurso formativo compromissado com a formação humana dos indivíduos, visto que os educadores/as de jovens e adultos lidam com pessoas que ficaram à margem dos processos de escolarização, sujeitos, muitas vezes, ausentes de experiências escolares de cunho humano. Obstina-se, assim, uma formação que não se limite simplesmente à transmissão de conhecimentos, mas que igualmente propicie reflexão crítica e emancipação cidadã.

Esse não é um pensamento recente nos diálogos e nas referências acerca da EJA. Desde o final da década de 1950, as considerações do educador Paulo Freire $(1963 ; 1970 ; 1996)$ sobre a teoria e a prática de uma educação transformadora, especialmente na Educação de Jovens e Adultos, vêm inspirando e orientando o campo educacional ao redor do mundo. Paulo Freire propunha uma educação libertadora e humanizada, direcionada para uma sociedade que sente, ouve e pensa. Uma proposta que representa a interdisciplinaridade, a construção do conhecimento por meio da articulação dos saberes e das vivências individuais e coletivas dos sujeitos alunos.

O educador de adultos, nesse contexto, reconhece e valoriza os estudantes jovens e adultos como seres de identidade histórica e cultural (MIRANDA; BARROSO, 2007), respeitando e interagindo a partir de suas experiências e vivências pregressas à escola. 
Passadas quase seis décadas, o pensamento de Freire mostra-se contemporâneo e inovador e, em certa medida, cabe à sociedade brasileira reflexão crítica por não ter plenamente implantado, em nosso sistema educacional, a forma de compreensão de mundo e de pessoas aludida por Paulo Freire.

\section{METODOLOGIA}

Os procedimentos desta pesquisa tiveram como objetivo realizar um levantamento bibliográfico teórico a respeito das informações relevantes ao campo da formação docente na Educação de Jovens e Adultos. O levantamento e/ou a revisão bibliográfica, de acordo com Pimentel (2001), proporciona análise interpretativa, ao mesmo tempo em que alinha uma direção de percurso e/ou pensamento de uma reflexão crítica proposta. Sendo assim, ao referenciar teoricamente a problemática abordada, buscou-se delinear as representações e as instâncias da formação docente na Educação de Jovens e Adultos, de acordo com as necessidades históricas e específicas do campo de pesquisa na EJA.

A realização de um levantamento bibliográfico busca proporcionar fundamentação teórica às discussões e aos resultados da análise de pesquisa proposta. Cunha (2001) reflete que, após escolhido o tema da investigação, faz-se necessário definir quais fontes de informação serão usadas para dar suporte a argumentos e a hipóteses. Ainda segundo o referido autor, a pesquisa científica acadêmica exige uma estruturação bibliográfica, no sentido de apurar os principais conceitos a respeito da temática abordada. No caso da delimitação aqui referenciada, referente à formação docente na EJA, foi preciso obter fontes que expressassem as realidades contextuais do campo prático da Educação de Jovens e Adultos, uma vez que as carências da ação docente intencionam as demandas pela formação de educadores.

\section{Especificidades da formação docente na EJA}

Em termos de processo formativo de educadores, a Educação de Jovens e Adultos não tem se diferenciado muito das outras modalidades educacionais. Sem uma formação específica, que capacite professores e professoras com os devidos recursos teóricos e práticos para a alfabetização e a escolarização de jovens e adultos, os docentes da EJA tendem a reproduzir, na Educação de Jovens e Adultos, as mesmas práticas desenvolvidas em outras modalidades educacionais. Isso tem sido um empecilho para uma prática docente de ação mais progressista e conscientizadora, no sentido de contribuir para uma análise mais crítica das realidades e dos contextos sociais, por parte dos educandos. Nas palavras de Moura:

$\mathrm{Na}$ maioria das vezes, os professores utilizam 0 mecanismo da reprodução do seu processo de escolarização para determinar a metodologia de trabalho nas salas de EJA. Não possui os fundamentos que lhes permitam incluir referenciais teóricometodológicos próprios à área. Esses referenciais teóricos possibilitariam ao professor a compreensão do ato de alfabetizar e escolarizar, permitindo que não mais ignore a complexidade do processo para o qual necessitará de conhecimentos

específicos.

Esses conhecimentos

permitiriam

a

compreensão

das

características

especificidades dos alunos

nos aspectos

antropológico, histórico, filosófico, cultural, psicológico,

sociolinguístico. Com essa base é possível entender e colocar, na prática cotidiana, questões e problematizações dos conteúdos das áreas específicas como matemática, linguagem, ciências sociais e naturais criando e desenvolvendo, junto com os alunos, numa perspectiva de mediação, processos metodológicos inovadores que possibilitem aos sujeitos a apropriação das habilidades básicas e essenciais de leitura, escrita e conhecimentos 
gerais (MOURA, 2008, p. 48-49).

Dessa forma, a EJA carece de processos de formação inicial e continuada de professores, que evidenciem, desde a formação profissional, as especificidades do ensino voltado para as pessoas jovens e adultas. Nesse sentido, Soares (2015, p. 14) explica que "o termo especificidade tem sido muito usado no campo da Educação de Jovens e Adultos, geralmente quando se faz referência a questões que estariam ligadas à sua qualidade". Isso porque o termo especificidade abarca particularidade e, no caso dos processos de formação profissional na EJA, evidenciaria as singularidades teóricas e práticas da atuação docente na Educação de Jovens e Adultos.

A formação de educadores de jovens e adultos possui particularidades que envolvem características do campo prático da EJA. Sendo assim, é preciso (re) conhecer e contextualizar as singularidades da Educação de Jovens e Adultas, de modo que seja possível definir conceitos e parâmetros para uma formação docente congruente com as realidades da modalidade de educação em questão. Primeiramente, é preciso (re) afirmar a relevância da educação popular no campo da educação de pessoas jovens e adultas. Nessa perspectiva, Brandão (2002, p. 142) conceitua a educação popular como uma proposta educacional baseada em "relações pedagógicas de teor político, realizadas através de um trabalho cultural estendido a sujeitos das classes populares compreendidos não como beneficiários tardios de um serviço, mas como protagonistas emergentes de um processo". No que se refere à Educação de Jovens e Adultos, a educação popular envolve a compreensão e a valorização cultural das grandes massas populares, público frequente na EJA, de modo que os estudantes jovens e adultos, advindos das classes populares, tenham condições de aprender a partir da sua própria cultura (PAIVA, 1984).

A educação popular representa, assim, recapitulando o pensamento de Paulo Freire (1970) sobre os posicionamentos políticospedagógicos da prática educativa, a integração e a participação das massas populares nas decisões que envolvem o meio educacional. Essa participação popular necessariamente envolve a participação em conselhos municipais e/ou regionais de ensino, passa pelo entendimento do espaço de luta política que a escola representa e chega até as reivindicações por políticas educacionais efetivas para as classes populares (FREIRE, 2000). Nesse entendimento, Freire (2000) também esclarece que a escola deve ser um espaço de organização e de contestação política, além de um ambiente de difusão do conhecimento e da cultura. Pensamento este que se alinha diretamente com as realidades e as premências da Educação de Jovens e Adultos. Entende-se, portanto, que as reflexões sobre a EJA passam inevitavelmente pela articulação com a educação popular, uma vez que a exclusão escolar inerente à educação de pessoas adultas atinge diretamente as classes populares (ESTEBAN, 2007).

Outro fator igualmente relevante, nas singularidades presentes na formação do educador de jovens e adultos, é a afirmação da identidade dos sujeitos alunos da EJA. Esses discentes são, na maioria das vezes, trabalhadores estudantes, mães e pais de família, geralmente advindos das classes populares e com um histórico particular de exclusão escolar. Tratase, pois, de um público diverso, cujos percursos e cujas experiências pregressas não podem ser ignoradas. Nessa perspectiva, Giovanetti (2005) avalia que a EJA possui marcas identitárias, respectivas à origem social de seus educandos e às concepções de educação que esses educandos possuem. Todos esses fatores, que caracterizam a Educação de Jovens e Adultos, têm de integrar as reflexões nos processos formativos dos docentes para a EJA.

Observa-se, assim, que discussões e reflexões em torno das identidades e das diversidades inerentes à EJA precisam integrar a ação formativa dos educadores de jovens e adultos. Sobre isso, Soares e Vieira (2009) avaliam que um dos focos da formação docente na EJA deve ser o (re) conhecimento da diversidade de sujeitos e das trajetórias humanas destes. Ainda segundo Soares e Vieira:

Um dos elementos que
precisam ser priorizados
na formação desse
educador está no reforço
da identidade da EJA, em
suas vinculações com o
ideário da educação
popular e os movimentos
sociais. Trata-se de
reconhecer que a EJA se
constituiu em uma área de
fronteiras entre os
movimentos sociais e as
instituições

Um dos elementos que precisam ser priorizados na formação desse educador está no reforço da identidade da EJA, em suas vinculações com o ideário da educação popular e os movimentos sociais. Trata-se de reconhecer que a EJA se constituiu em uma área de os instituições 
governamentais e, portanto, herdou muitas das contribuições do movimento de educação popular. Nessa perspectiva, as políticas de formação não podem perder o foco na própria história da EJA. Da sua estreita relação com os movimentos sociais emancipatórios e de lutas pela formação do direito à educação como bem social ao qual todos devem ter acesso (SOARES; VIEIRA, 2009 , p. $156-157)$.

Dessa forma, a EJA, assim como os educandos dessa modalidade de educação, possui identidades fundamentadas na diversidade e na pluralidade. Compreende-se, então, que um dos pontos de partida para a construção de processos de formação docente, na Educação de Jovens e Adultos, é o entendimento dessa diversidade e pluralidade. Conforme explanam Jardilino e Araújo (2014, p. 171), as ações específicas, na Educação de Jovens e Adultos, precisam "conhecer os sujeitos da EJA, suas trajetórias, identificando seu perfil, suas expectativas e vivências, para que eles possam ser considerados na construção de propostas que venham atender-lhes de maneira específica". Trata-se de reconhecer esses discentes como sujeitos detentores de direitos, de valorizá-los para além da perspectiva de exclusão, de superar visões estereotipadas e preconceituosas sobre aqueles que não tiveram acesso à escola (JARDILINO; ARAúJO, 2014).

Paralelamente ao reconhecimento e às reflexões acerca da identidade dos jovens e adultos que frequentam a EJA, é necessário haver a estruturação de uma proposta curricular que capacite os educadores de jovens e adultos no domínio dos conhecimentos e dos saberes coletivos inerentes à Educação de Jovens e Adultos (ARROYO, 2006). Além de focar na história de lutas característica à EJA, um currículo de formação de educadores de jovens e adultos precisa alinhar-se com a cultura popular, de modo a responder os questionamentos dos representantes das classes populares e enriquecê-los culturalmente a partir da valorização de sua própria cultura (ARROYO, 2006).
A referida perspectiva curricular, embasada em concepções teóricas, voltadas para as pertinências do campo prático da EJA, certamente, auxiliaria na elaboração de uma atividade docente mais dialógica no ensino de pessoas jovens e adultas. De acordo com Ferro e Pinheiro (2015), faz-se necessário elaborar uma proposta curricular, no campo da formação docente na Educação de Jovens e Adultos, voltada para a diversidade, visto que as sociedades contemporâneas estão imersas em multiculturalismo. Nesse sentido, discutir a ação docente na EJA implica refletir sobre as propostas curriculares na formação docente nessa modalidade educacional e a relação dessas propostas com a diversidade social e cultural. Face às diferenças socioculturais dos estudantes da Educação de Jovens e Adultos, Ferro e Pinheiro (2015) avaliam que as dimensões formativas e curriculares na EJA devem ser fundamentadas no multiculturalismo, de modo a favorecer os processos democráticos e eliminar conceitos de discriminação e de preconceito.

Percebe-se que as especificidades da EJA aqui relacionadas fundamentam uma proposta de formação docente dialógica, atrelada à diversidade de conhecimentos e de saberes e em harmonia com as urgências do campo da Educação de Jovens e Adultos. A ênfase no legado da educação popular, no respeito à identidade dos educandos da EJA e na construção de uma proposta curricular formativa, que corresponda às realidades da prática de ofício, representa a opção por uma concepção de formação que reconhece e enaltece o que a EJA simboliza como história, como trajetória de lutas e como projeção futura (ARROYO, 2006).

Sendo assim, a formação de educadores na EJA necessita de proposições que evidenciem e capacitem educadores e educadoras nas concepções e nas práticas da Educação de Jovens e Adultos. Intencionam-se, conforme Santos e Campos (2009, p. 41), ações educativas sustentadas por uma perspectiva intercultural, o que "pressupõe um processo dinâmico e permanente de relação, de comunicação e de aprendizagem entre culturas em condição de respeito, legitimidade mútua, simetria e igualdade".

\section{A Identidade do Educador de Jovens e Adultos A profissão docente exige} comprometimento ideológico, preparação técnica, conhecimentos pedagógicos e tantas 
outras capacitações por parte dos docentes que assumem responsabilidades complexas e desafiadoras no construto de uma sociedade democrática e igualitária (SONNEVILLE; JESUS, 2009). Dessa forma, os profissionais docentes têm de se identificar com os processos educativos dos quais fazem parte, o que, necessariamente, envolve referências objetivas e/ou subjetivas de viés ideológico, político e social, em amplitude pessoal e/ou coletiva. No que diz respeito ao processo de identificação docente, Caldeira (2000, p. 2) explica que:

Comor sujeito
sociocultural, o/a
professor/a constrói sua
identidade profissional a
partir de inúmeras
referências. De um lado,
estão a significação social
da profissão e as relações
com as instituições
escolares, com outros
docentes, com as
associações de classe, etc.
De outro lado, está o
significado que cada
professor/a confere ao seu
trabalho docente, o que
inclui desde sua história
familiar, sua trajetória
escolar e profissional, até
seus valores, interesses e
sentimentos, suas
representações e saberes,
enfim, o sentido que tem
em sua vida o ser
professor/a (CALDEIRA,
2000, p. 2). r a

Nessa abordagem, especificamente versando sobre a EJA, educadores de jovens e adultos precisam estar identificados com as reivindicações, as propostas, as diversidades e os contextos da Educação de Jovens e Adultos. Diniz-Pereira e Fonseca (2001) avaliam que o reconhecimento das especificidades da EJA aponta para a construção de elementos de identificação docente neste contexto. Considerando que a EJA é uma modalidade de educação situada no âmbito da justiça social, no desenvolvimento das potencialidades humanas e na luta pela equidade de direitos, objetiva-se que os docentes que atuam nesse âmbito estejam conscientes dos contextos históricos e das relações sociais que a constituem. (VENTURA; BONFIM, 2015).
Assim sendo, a identificação docente dos educadores de jovens e adultos com as características dessa modalidade parte do pressuposto de que esses educadores estejam conscientes das diferenciações do campo educacional em questão. Contudo, muitas vezes, a constituição da identidade docente somente ocorre no exercício profissional. Quanto a essa questão, Diniz-Pereira e Fonseca evidenciam:

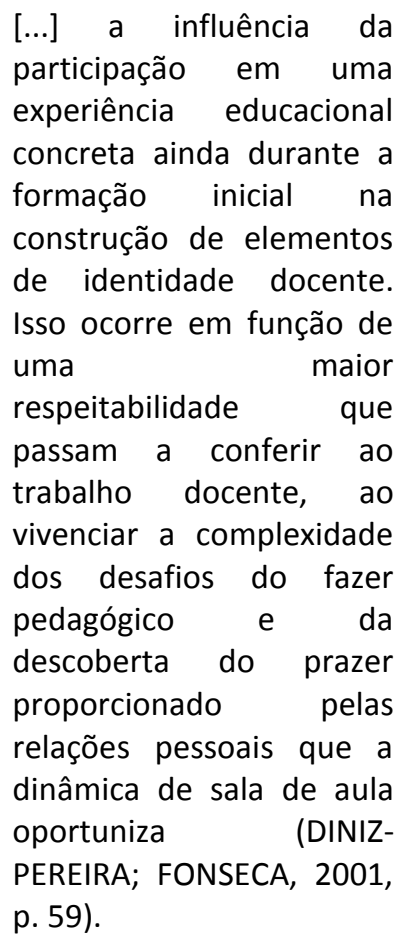

Dessa forma, o posicionamento construtivo que desenvolve o conceito de identidade profissional docente está relacionado a experiências concretas de prática educativa. A partir do momento em que se assume o papel de professor, colocando-se diante de outras pessoas e reconhecendo-as como estudantes, e identificando-se como educador, é que se inicia o processo de identificação docente (DINIZPEREIRA; FONSECA, 2001). Ainda que esses educadores possuíssem interesses pregressos, ou tivessem se imaginado na condição de professor anteriormente, é somente a partir de experiências concretas de prática docente que a identificação profissional se concretiza. No que se refere ao ensino de jovens e adultos, as possibilidades de identificação profissional são prejudicadas pela falta de uma formação inicial específica de educadores de adultos, o que resulta em possíveis conflitos de embasamento teórico e/ou prático na atividade docente (DINIZPEREIRA; FONSECA, 2001).

Ao abordar a necessidade de identificação por parte dos educadores com os 
contextos da EJA, igualmente se faz necessário conhecer as origens, as hesitações e os questionamentos desses docentes. Muitas vezes, o professor de jovens e adultos possui idade inferior a de seus alunos e pode sentir-se intimidado e/ou despreparado para lidar com a diversidade presente no contexto escolar da EJA. Conforme analisam Leite e Gazoli (2012), são muitos os aspectos a serem considerados na construção de uma proposta docente na Educação de Jovens e Adultos. Cabe aos educadores de jovens e adultos o planejamento organizacional da ação docente, a partir da contextualização dos saberes dos alunos, além do respeito a diferentes formas e tempos de aprendizado. Não se pode, por exemplo, correr o risco de utilizar, na EJA, atividades escolares bem-sucedidas nas modalidades da educação básica ofertadas para estudantes em idade regular, pelo simples pensamento de que elas também terão sucesso na EJA (LEITE; GAZOLI, 2012).

A EJA caracteriza-se pela experiência vivencial de seus alunos, o que requer uma ação docente crítica e atenta aos possíveis efeitos dessa prática educativa no cotidiano dos educandos. Sendo assim, para Soares (2003), a Educação de Jovens e Adultos, nos dias de hoje, depara-se com a complexidade de construir uma edificação educacional equilibrada e humanizada, com uma estrutura de ensino capaz de suprir as expectativas em torno da prática docente. Para tanto, torna-se necessária uma formação docente específica, que proporcione embasamento teórico e autoconhecimento aos futuros professores e professoras da EJA. Acerca dessa temática, Soares afirma que:

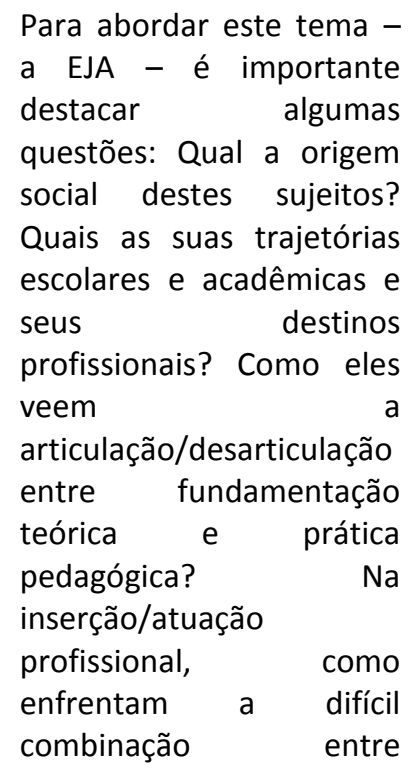

docência e pesquisa? Os estudantes que também trabalham se identificam com o público da Educação de Jovens e Adultos - EJA? Esse fato tem alguma consequência em suas práticas pedagógicas? Como esses profissionais, na medida em que atuam em uma entidade próxima do aluno trabalhador, percebem a articulação/desarticulação entre a sua dimensão política e a dimensão pedagógica? $\mathrm{Na}$ visão do egresso, o tempo dedicado à habilitação foi suficiente? Além das aulas, que outras estratégias fizeram parte dessa formação? Quais questões foram consideradas fundamentais na discussão teórico metodológica no campo da Educação de Jovens e Adultos? Quais foram os impactos que esses processos formativos têm tido na prática cotidiana do professor? (SOARES, 2003, p. 121).

Dessa forma, a construção de uma formação docente capaz de abordar conceitos e práticas contextuais à EJA também passa pelas experiências anteriores, pelas descobertas e pelos objetivos do educador de jovens e adultos. Existe uma trajetória em torno da formação desse docente que não pode ser desconsiderada, uma vez que a Educação de Jovens e Adultos apresenta situações que exigem compreensão a respeito da realidade social dos sujeitos alunos dessa modalidade educacional (BORGHI, 2007).

No caso da EJA, uma das maiores dificuldades na contemporaneidade é a formação de um profissional docente consciente da importância de práticas pedagógicas inovadoras e humanas, portador de uma metodologia que busque incorporar ao processo educativo diversidade de temas e de propostas, objetivando sempre a transformação dos indivíduos culturalmente. Nesse sentido, Soares (2003) considera que as dificuldades encontradas no âmbito da formação profissional prejudicam a 
prática docente, uma vez que o profissional nem sempre apresenta preparo suficiente para enfrentar as realidades nem sempre amistosas da Educação de Jovens e Adultos.

Freire (1996), em sua obra clássica "Pedagogia da Autonomia", faz ponderações a respeito da ausência de reflexão crítica na prática educativa cotidiana. Segundo o autor, essa ausência reflexiva advém de uma formação docente que prioriza a repetição mecânica dos saberes, denominada, por Freire (1970), como educação bancária. Classificada como mera transmissão passiva de conteúdos do professor para o aluno, a educação bancária ignora a existência de conhecimentos exteriores à escola por parte dos educandos e possíveis relações de aprendizado entre docentes e discentes. Nesse sentido, e no caso específico da Educação de Jovens e Adultos, nega-se aos estudantes o compartilhamento de toda uma trajetória pessoal repleta de experiências de vida.

Inúmeras ações educacionais fracassaram pelo fato de não considerarem os estudantes como seres sociais pensantes, taxando-os apenas pelo desempenho no âmbito escolar. Obviamente, o fracasso dessas ações não pode simplesmente ser apregoado aos profissionais da educação. O êxito das práticas escolares está diretamente relacionado à abrangência das políticas públicas aplicadas no campo educacional. Em decorrência disso, entende-se que a inovação e a adequação dos processos de formação docente tornam-se reivindicações pertinentes para as políticas públicas no campo da educação.

\section{Políticas Públicas na Formação Docente na EJA}

Historicamente, as demandas da Educação de Jovens e Adultos no Brasil foram tratadas com políticas públicas marginais e de viés emergencial (DI PIERRO, 2001). Consequentemente, a ausência de políticas governamentais efetivas estabeleceu a EJA como um espaço de lutas, de reivindicações e de resistências. E, apesar dos avanços das últimas décadas, como o ingresso da EJA no Fundo de Manutenção e Desenvolvimento da Educação Básica -FUNDEB e a criação dos Fóruns de EJA, as políticas públicas destinadas à Educação de Jovens e Adultos ainda deixam a desejar. Nesse contexto, um dos pontos centrais, nas discussões sobre as políticas públicas na EJA, é a formação de educadores para essa modalidade de educação. Citando Di Pierro:
A formação inicial e continuada de educadores é um dos temas abordados com prioridade pelos fóruns de EJA que, convencidos de que a educação de jovens e adultos guarda especificidades relacionadas às identidades e características sociais, psicológicas e culturais dos sujeitos de aprendizagem, há longa data reivindicam espaços e processos próprios de qualificação. (...) A agenda de diálogo, reivindicação e conflito dos fóruns com os governos exprime assim, em grande medida, os principais desafios das políticas de educação de jovens e adultos na atualidade (DI PIERRO, 2005, p. 1131-1132).

A necessidade de políticas públicas focadas na capacitação de educadores para EJA se impõe por uma multiplicidade de fatores e de questões. Verifica-se, a título de exemplo, grande dificuldade em estabelecer e consolidar espaços de formação, assim como a insistência em conceitos equivocados e discriminatórios que alocam a EJA em uma posição de inferioridade, de ensino compensatório e aberto à improvisação (DI PIERRO, 2005). A constatação dessa realidade tão somente corrobora a emergência de políticas públicas educacionais voltadas para a formação de professores/as na Educação de Jovens e Adultos.

A respeito disso, Diniz-Pereira (1999) afirma que as reivindicações pretendidas para a formação docente necessitam estar em consonância com as modificações pretendidas para a educação de forma geral. O profissional docente carece, em sua formação, de vivências oriundas da educação básica, desde a educação infantil, passando pela educação de adolescentes, até $\mathrm{o}$ ensino de jovens e adultos. A diversidade presente na realidade dos sujeitos educandos deve ser uma força motriz nos projetos pedagógicos de formação. Apesar dessa alusão, Diniz-Pereira (1999) considera que uma análise mais crítica do contexto educacional evidencia 
uma defasagem teórica e prática dos processos de formação. Como resultante, avalia-se que a atuação profissional de professores corra sérios riscos de improvisação, de aligeiramento e de desregulamentação.

A ausência de crítica e de reflexão na prática docente demonstra carências e descontinuidades no processo formativo educacional. Quando discutimos a formação docente do educador de jovens e adultos, temos que, necessariamente, argumentar pela precisão de formação humana no processo formativo desse educador. Nessa perspectiva, Moura (2007) ressalta que a objetividade pragmática de conceitos pedagógicos, encontrados em alguns processos de formação, tem sido um obstáculo para uma dialética constituinte de consciência reflexiva. Não obstante, a formação docente deve ser repleta de subjetividade, mas, diante de realidades estruturais que inibem práticas sociais de afeto, de compaixão e de justiça, torna-se indispensável a abordagem de uma subjetividade potencializada, que provoque e incite a interrogação crítica na formação docente.

Nesse contexto, Soares (2011, p. 287) aponta que um dos principais desafios da EJA atualmente é "a configuração de seu campo de estudo e de atuação, e como parte dessa configuração, situa-se a formação do educador de jovens e adultos para além dos cursos de pedagogia". Seguindo essa linha de raciocínio, faz-se necessária a afirmação de políticas públicas destinadas à formação específica de educadores de jovens e adultos. Mas o desenvolvimento dos processos formativos não se restringe somente a políticas de ação governamental, pois, cada vez mais, cresce a relevância e a participação da sociedade civil na formação profissional de educadores da EJA, por meio dos movimentos sociais, de organizações não governamentais e dos sindicatos. Trata-se de parcerias que enriquecem a disseminação de práticas docentes e de concepções formativas diversificadas, uma vez que alcançam diretamente o público característico da EJA (HADDAD; DI PIERRO, 2000).

Por essa razão, cabe ressaltar a importância de diferentes instâncias de políticas de formação docente para a Educação de Jovens e Adultos. De acordo com Barreto (2006), é preciso estabelecer distinções entre a formação inicial e a formação permanente dos educadores de jovens e adultos. A formação inicial integra um processo formativo que busca saber como agir e como ensinar na alfabetização e na escolarização de jovens e adultos. Esse processo formativo é, geralmente, caracterizado por contextualizações das diversidades socioculturais, políticas e econômicas da EJA, e tem como público-alvo docentes em formação, que ainda não tiveram experiências em sala de aula. A formação permanente, que igualmente pode ser configurada como formação continuada (BARRETO, 2006), estabelece o desenvolvimento de ações integradoras ao processo de formação inicial. Por meio da atividade docente cotidiana, educadores/as constatam as realidades do campo educacional e aperfeiçoam a prática profissional por meio de reflexões críticas.

O discurso apresentado demonstra que as políticas, em prol da formação profissional, precisam ser dinâmicas e contínuas. A educação é um campo complexo e multifacetado, e a formação profissional docente demanda ações instigadoras que proporcionem fluidez teórica e prática para lidar com os possíveis conflitos do oficio docente. Nesse sentido, políticas públicas afirmativas e contextualizadas com realidades do presente fazem-se necessárias para que o campo da Educação de Jovens e Adultos não continue, de acordo com o que descreve Soares (2011, p. 86), como "um lote vago" ou uma "terra sem dono".

Diante da necessidade da afirmação de políticas públicas em favor da formação docente na Educação de Jovens e Adultos, outro fator preponderante é o incentivo em pesquisas em benefício dessa formação. Diniz-Pereira et al. (2008) ressalta que ainda se sabe pouco a respeito do docente da EJA. Obviamente, em decorrência das particularidades dessa modalidade de educação, e ainda segundo DinizPereira et al. (2008), todo professor de jovens e adultos é um educador militante. Porém, quais as razões dessa militância? Quais são as identidades e as singularidades da formação desse educador? Diante desses questionamentos, é preciso incentivar e aprofundar as pesquisas em prol da formação do educador de jovens e adultos, de forma a formular estratégias e ações concretas na formação de novos docentes, que possam se reverter em políticas públicas eficazes para essa modalidade de educação.

Observa-se a necessidade de problematizar as concepções, as metodologias e as ações que perpassam a formação de professores da EJA. Tendo em vista as singularidades que marcam os educandos da EJA e a tentativa de ampliar o processo educativo dos 
diversos sujeitos presentes na Educação de Jovens e Adultos, faz-se necessária a fomentação de políticas públicas que estabeleçam propostas humanizadas de formação e de capacitação docente. A respeito da construção de um processo educacional de formação humana e emancipatória na EJA, Ventura avalia que é preciso:

[...] trazer para o âmbito

da formação de

professores,

principalmente no que se refere aos cursos de

licenciatura das disciplinas escolares, reflexões sobre o que é a EJA e que tipo de formação humana desejamos construir com esses jovens e adultos, apontando coletivamente para o horizonte de uma formação que contribua para a emancipação dos sujeitos como possibilidade de transformação social e de construção de um projeto societário contra hegemônico; portanto, que ultrapasse concepções e práticas conformadoras à ordem, articulando a EJA à luta por transformações estruturais na sociedade (VENTURA, 2012, p. 80).

A afirmação de Ventura (2012) expressa um relevante questionamento a respeito dos posicionamentos conceituais e metodológicos para a formação de educadores de pessoas jovens e adultas. As recentes ações governamentais para a modalidade EJA ${ }^{1}$ vêm priorizando fatores ligados à afirmação de propostas legislativas, à oferta de vagas, à qualificação profissional de trabalhadores e à estruturação de currículos escolares, no sentido de reconhecer e de estabelecer a Educação de Jovens e Adultos como uma modalidade efetiva perante o meio educativo. A formação de

\footnotetext{
${ }^{1}$ Entenda-se: o Plano Nacional de Qualificação dos Trabalhadores (PLANFOR), o Plano Nacional de Qualificação (PNQ), o Projeto Escola de Fábrica, o Programa Nacional de Inclusão de Jovens: Educação, Qualificação e Ação Comunitária (PROJOVEM), o Programa Nacional de Integração da Educação Profissional com a Educação Básica na Modalidade de Educação de Jovens e Adultos (PROEJA) e o Programa Nacional de Acesso ao Ensino Técnico e Emprego (PRONATEC).
}

educadores para a EJA, no entanto, apresenta lacunas formativas que dificultam a preparação de profissionais realmente capacitados para essa modalidade educacional. Ventura; Bonfim (2015) aponta diversos estudos (DI PIERRO, 2006; SOARES, 2008; PORCARO, 2011) que evidenciam o desconforto e a insegurança dos professores que atuam na Educação de Jovens e Adultos, diante dos contrastes entre a formação profissional adquirida e as realidades encontradas no campo escolar da modalidade de educação em questão.

Por isso, a política pública almejada para a formação de educadores de jovens e adultos precisa considerar os principais fatores que expressam as especificidades do campo da EJA. Como aponta Arroyo (2006), os futuros professores da EJA devem saber distinguir os anseios do público da Educação de Jovens e Adultos e diferenciar o que é ser jovem e o que é ser adulto, mas não qualquer jovem ou qualquer adulto, mas sim o que é ser um jovem e/ou adulto que frequenta a EJA. Para tanto, é preciso superar paradigmas e atenuações de inferioridade que ainda são atribuídos à Educação de Jovens e Adultos. Além disso, é preciso construir políticas públicas, em parceria com a sociedade, que visem à formação inicial e continuada de educadores de jovens e adultos (VENTURA; BONFIM, 2015).

Observa-se, assim, a necessidade de refletir criticamente sobre $\mathrm{o}$ processo de formação docente na EJA e de (re) avaliar as possibilidades e/ou intencionalidades desse processo. É preciso reforçar os debates em torno da emergência de resoluções que ampliem a potencialidade docente na Educação de Jovens e Adultos, incentivando, portanto, o aperfeiçoamento da prática escolar na EJA, mediante políticas públicas efetivas de formação profissional docente.

\section{CONSIDERAÇÕES FINAIS}

A Educação de Jovens e Adultos carece de estudos que aprofundem os conhecimentos sobre os processos formativos dessa modalidade de educação e que contribuam para a elaboração de instrumentos teóricos para a formação docente de educadores de jovens e adultos. Nessa perspectiva, esta pesquisa, por meio da análise bibliográfica teórica, no campo da formação profissional na Educação de Jovens e Adultos, reitera a necessidade de propostas curriculares, assim como de espaços de formação 
inicial e continuada de professores/as, com características e especificidades formativas voltadas para a EJA.

Nesse contexto, entende-se, a partir da reflexão dos autores analisados, que os processos formativos na Educação de Jovens e Adultos devem optar pelo diálogo e pela contextualização das realidades históricas dessa modalidade de educação. Propostas formativas desenvolvidas a partir do compartilhamento democrático de ideias, que respeitem a diversidade de pensamentos, devem ser incentivadas. Obviamente, as propostas pedagógicas construídas nem sempre ocorrerão como planejado, o que não quer dizer que elas fracassaram. Muitas delas serão retificadas ou reconstruídas para melhor eficácia. 0 importante é que elas intercorram em um regime democrático de opiniões.

Por fim, as considerações desta investigação avaliam que a formação docente na EJA perpassa pela renovação dos conceitos sobre a atividade educativa cotidiana. As experiências formativas devem estimular o desenvolvimento e a reflexão acerca das teorias e das metodologias docentes previamente adquiridas nos cursos de formação, estabelecendo, assim, que a continuidade do aprendizado docente é algo inerente à prática da atividade educacional. É preciso, pois, redimensionar e fomentar a construção de processos de formação de profissionais docentes mais dialógicos e estruturados às realidades dos educandos. Dessa forma, as proposições almejadas para formação de educadores/as de jovens e adultos precisam proporcionar descobertas, não somente pedagógicas, mas igualmente de caráter vocacional.

Espera-se que este estudo tenha se configurado positivamente diante das questões que envolvem a Educação de Jovens e Adultos como uma modalidade de educação preponderante, em especial na temática da formação de educadores/as. Novas indagações são necessárias, para que outros questionamentos sejam abordados e outras reflexões sejam feitas. Em meio a essas questões, uma se sobressai: a necessidade de diálogo democrático nas formas de argumentar, de refletir e de formar novos professores/as.

\section{REFERÊNCIAS}

ARROYO, M. Formar educadoras e educadores de jovens e adultos. In: SOARES, L. (Org.). Formação de Educadores de Jovens e Adultos. Belo Horizonte: Editora Autêntica/SECADMEC/UNESCO, 2006, p. 17-32.

ARROYO, M. Tensões na condição e no trabalho docente - tensões na formação. Movimento Revista de Educação, v. 2, n. 2, p. 1-34, 2015. Disponível em: <http://www.revistamovimento.uff.br/index.php /revistamovimento/article/view/251>. Acesso: 15 jul. 2018.

BARRETO, V. Formação Permanente ou Continuada. In: SOARES, L. (Org.). Formação de Educadores de Jovens e Adultos. Belo Horizonte: Editora Autêntica/SECAD-MEC/UNESCO, 2006, p. 93-102.

BORGHI, I. S. M. Formação de educadores da EJA: inquietações e perspectivas. Revista Diálogos Possíveis, v. 6, n. 2, p. 227-238, jul./dez. 2007.

BRANDÃO, C. R. A educação como cultura. São Paulo: Brasiliense, 2002.

CALDEIRA, A. M. S. A história de vida como instrumento para compreensão do processo de construção da identidade docente. Encontro Nacional de Didática e Prática de Ensino (ENDIPE): Rio de Janeiro, p. 29-40, 2000.

CUNHA, M. B. Para Saber Mais: fontes de informação em ciência e tecnologia. Brasília: Briquet de Lemos/Livros, 2001.

DINIZ-PEREIRA, J. E. As licenciaturas e as novas políticas educacionais para a formação docente. Revista Educação \& Sociedade, v.20, n.68, p. 109-125, Dez./1999. Disponível em: $<$ http://www.scielo.br/pdf/es/ v20n68/a06v2068.pdf>. Acesso: 01 ago. 2018.

DINIZ-PEREIRA, J. E. ET AL. Aprender a ser educador da EJA: análise de memoriais de professores-monitores do PROEF/UFMG. In: DINIZ-PEREIRA, J. E.; LEÃO, G.. (Org.). Quando a diversidade interroga a formação docente. Belo Horizonte: Autêntica Editora, 2008, p. 77-107.

DINIZ-PEREIRA, J. E.; FONSECA, M. C. F. R. Identidade docente e formação de Educadores de Jovens e Adultos. Rev. Educação e Realidade, Porto Alegre, v.26, n.2, p. 51-73, 2001. Disponível em: 
<http://seer.ufrgs.br/educacaoerealidade/article /view/26138>. Acesso: 07 ago. 2018.

DI PIERRO, M. C. Descentralização, focalização e parceria: uma análise das tendências nas políticas públicas de educação de jovens e adultos. Educação e Pesquisa (USP), São Paulo, p. 321338, 2001. Disponível em: <http://www.scielo.br/scielo.php?script=sci_artt ext\&pid=S151797022001000200009>. Acesso: 05 ago. 2018.

ESTEBAN, M. T. Educação popular: desafio à democratização da escola pública. Cad. CEDES, Campinas, v. 27, n. 71, p. 9-17, abr. 2007. Disponível em: <http://https://bit.ly/2JOxyxD>. Acesso: 05 ago. 2018.

FERRO, J. I.; PINHEIRO, R. A. A ação docente e o Currículo na EJA: um repensar a partir das diferenças socioculturais dos alunos. Revista Brasileira de Educação de Jovens e Adultos, v. 3, n.5, p. 99-120, 2015. Disponível em: <http://www.revistas.uneb.br/index.php/educajo venseadultos/article/view/1388. Acesso: 07 ago. 2018.

FREIRE, P. Alfabetização e Conscientização. Porto Alegre: Editora Emma, 1963.

FREIRE, P. Pedagogia da Autonomia: saberes necessários a prática educativa. 26. ed. São Paulo: Editora Paz e Terra, 1996.

FREIRE, P. Pedagogia do Oprimido. 11. ed. Rio de Janeiro: Editora Paz e Terra, 1970.

GIOVANETTI, M. A. A Formação de Educadores de EJA: o legado da educação popular. In: SOARES, L.; GIOVANETTI, M. A.; GOMES, N. Diálogos na Educação de Jovens e Adultos. Belo Horizonte: Editora Autêntica, 2005, p. 233-254.

HADDAD, S.; DI PIERRO, M. C. Escolarização de jovens e adultos. Revista Brasileira de Educação, São Paulo, n. 14, p. 108-130, 2000. Disponível em:<http://www.scielo.br/pdf/rbedu/n14/n14a0 7.pdf >. Acesso: 10 ago. 2018.

JARDILINO, J. R. L.; ARAÚJO, R. M. B. Educação de Jovens e Adultos - sujeitos, saberes e práticas. São Paulo: Editora Cortez, 2014.
LEITE, S. S.; GAZOLI, D. G. D. Afetividade no processo de alfabetização de jovens e adultos. EJA em debate, Florianópolis, v. 1, n. 1, p. 79-104, nov. 2012. Disponível em: <http://incubadora.periodicos.ifsc.edu.br/index.p hp/EJA/article/view/314\#.WAH9qIQrKM8>.

Acesso: 15 jul. 2018.

MIRANDA, K. C. L.; BARROSO, M. G. T. A contribuição de Paulo Freire à prática e educação crítica em enfermagem. Rev. Latino-Am. Enfermagem, Ribeirão Preto, v. 12, n. 4, p. 631635, ago. 2004. Disponível em: <http://www.scielo.br/scielo.php?script=sci_artt ext \&pid=S010411692004000400008\&lng=en \&nr m=iso>. Acesso: 25 ago. 2018.

MOURA, T. M. M. Alfabetização e Letramento na formação de alfabetizadores de jovens e adultos. (Org.). In: MOURA, T. M. M. (Org.). A Formação de Professores para a EJA: Dilemas Atuais. Belo Horizonte: Ed. Autêntica, 2008, p. 11-38.

NÓVOA, A. Formação de Professores e Profissão Docente. FPDC-UOE-HEEC, Faculdade de Lisboa. Lisboa, 2007. Disponível em: <http://repositorio.ul.pt/handle/10451/4758>. Acesso: 05 ago. 2018.

NOVOA, A. Para uma formação de professores construída dentro da profissão. Revista de Educacíon, n. 350, Madrid, set-dez, 2009. Disponível em: <http://www.revistaeducacion.educacion.es/re3 50/re350_09por.pdf>. Acesso: 17 jul. 2018.

PAIVA, V. P. Educação popular e educação de jovens e adultos: contribuição à história da educação brasileira. São Paulo: Loyola, 1984.

PIMENTEL, A. O método da análise documental: seu uso numa pesquisa historiográfica. Cadernos de Pesquisa, São Paulo, n. 114, p. 179195, Nov. 2001. Disponível em: $<$ http://www.scielo.br/scielo.php?script=sci_artt ext\&pid=S0100$15742001000300008 \& \operatorname{lng}=e n \& n r m=i s o>$. Acesso: 20 ago. 2018.

PORCARO, R. C. Os desafios enfrentados pelo educador de jovens e adultos no desenvolvimento de seu trabalho docente. EccoS Revista Científica, no 25, jan-jun, p. 39-57, 2011. Disponível 
<http://www.redalyc.org/articulo.oa?id=7152170 8003 >. Acesso: 05 ago. 2018.

RIBAS, M. S.; SOARES, S. T. Formação de Professores para atuar na Educação de Jovens e Adultos: uma reflexão para o desenvolvimento e aperfeiçoamento da prática docente. In: SEMINÁRIO DE PESQUISA EM EDUCAÇÃO DA REGIÃO SUL - ANPED SUL, 9, Caxias do Sul - RS. Anais...Caxias do Sul: Universidade de Caxias do Sul, 2012, p. 01-16.

SANTOS, E. P.; CAMPOS, R. C. Sujeitos da Igualdade e da Diferença na Interculturalidade. In: SOARES, L.; SILVA, I. O. Sujeitos da Educação e Processos de Sociabilidade - os sentidos da experiência. Belo Horizonte: Editora Autêntica, 2009, p. 23-51.

SOARES, L. Analisando pesquisas de Educação de Jovens e Adultos. In: SOARES, L. Educação de Jovens e Adultos - o que revelam as pesquisas. Belo Horizonte: Editora Autêntica, 2011, p. 15-22.

SOARES, L. A Formação do Educador de Jovens e Adultos. In: SOARES, L. (Org.). Aprendendo com a Diferença: Estudos e Pesquisas em Educação de Jovens e Adultos. Belo Horizonte: Editora Autêntica, 2003, p. 121- 141.

SOARES, L. A Formação de Educadores e as Especificidades da Educação de Jovens e Adultos em Propostas de EJA. In: SEMINÁRIO NACIONAL SOBRE FORMAÇÃO DE EDUCADORES DE JOVENS, E ADULTOS, 5., Campinas. Anais... Campinas - SP: UNICAMP, p. 1-18, 2015. Disponível em: http://sistemas3.sead.ufscar.br/snfee/index.php/ snfee/article/view/197/76. Acesso: 25 ago. 2018.

SOARES, L. O educador de jovens e adultos e sua formação. Educ. Rev., Belo Horizonte, n. 47, p. 83-100, Jun. 2008. Disponível em: <http://www.scielo.

$\mathrm{br} /$ scielo.php?script=sci_arttext\&pid=S0102-

46982008000100005\&lng=en\&nrm=iso >. Acesso: 20 ago. 2018.

SOARES, L.; VIEIRA, M. C. Trajetórias de formação: contribuições da Educação Popular à configuração das práticas de Educação de Jovens e Adultos. In: SOARES, L.; SILVA, I. O. Sujeitos da Educação e Processos de Sociabilidade sentidos da experiência. Belo Horizonte: Editora Autêntica, 2009, p.153-178.
SONNEVILLE, J. J.; JESUS, F. P. Complexidade do Ser Humano na Formação de Professores. In: NASCIMENTO, A. D.; HETKOWSKI, T. M (Orgs.). Educação e Contemporaneidade - pesquisas científicas e tecnológicas. Salvador: EDUFBA, 2009, p. 295-320.

VENTURA, J. A EJA e os Desafios da formação Docente nas Licenciaturas. Educação e Contemporaneidade, Salvador, v. 21, n. 37, p. 7182, jan./jun. 2012. Disponível em: <http://www.revistas.uneb.br/index.php/ faeeba/article/ view/458>. Acesso: 30 ago. 2018.

VENTURA, J.; BOMFIM, M. I. Formação de professores e Educação de Jovens e Adultos: o formal e o real nas licenciaturas. Educ. Rev., Belo Horizonte, v. 31, n. 2, p. 211-227, jul. 2015. Disponível em: <http://www.scielo.br/scielo.php?pid=S010246982015000200211\&script=sci_abstract \&tIng=p t >. Acesso: 11 out. 2018.

Recebido para avaliação: 10/09/2018

Revisado em: 09/11/2018

Aceite Final: 11/11/2018 